Alimentary Tract

\title{
Prevalence, incidence and risk factors for Helicobacter pylori infection in a cohort of Portuguese adolescents (EpiTeen)
}

\author{
Joana Bastos $^{\mathrm{a}, \mathrm{b}}$, Bárbara Peleteiro ${ }^{\mathrm{a}, \mathrm{b}}$, Hugo Pinto ${ }^{\mathrm{a}, \mathrm{b}}$, Ana Marinho ${ }^{\mathrm{c}}$, João T. Guimarães ${ }^{\mathrm{b}, \mathrm{c}, \mathrm{d}}$, \\ Elisabete Ramos $^{\mathrm{a}, \mathrm{b}}$, Carlo La Vecchia ${ }^{\mathrm{e}, \mathrm{f}}$, Henrique Barros ${ }^{\mathrm{a}, \mathrm{b}}$, Nuno Lunet $^{\mathrm{a}, \mathrm{b}, *}$ \\ a Department of Clinical Epidemiology, Predictive Medicine and Public Health, University of Porto Medical School, Porto, Portugal \\ ${ }^{\mathrm{b}}$ Institute of Public Health of the University of Porto (ISPUP), Porto, Portugal \\ ${ }^{c}$ Department of Clinical Pathology Service, Hospital São João Medical Center, Porto, Portugal \\ 'Department of Biochemistry, University of Porto Medical School, Porto, Portugal \\ e Department of Epidemiology, “Mario Negri” Institute for Pharmacologic Research, Milan, Italy \\ ${ }^{\mathrm{f}}$ Department of Medical Sciences and Public Health, University of Milan, Milan, Italy
}

\section{A R T I C L E I N F O}

\section{Article history:}

Received 4 September 2012

Accepted 18 November 2012

Available online 21 December 2012

\section{Keywords:}

Adolescents

Helicobacter pylori

Incidence

Portugal

Prevalence

\begin{abstract}
A B S T R A C T
Background: Helicobacter pylori infection is acquired mainly during childhood, but it may occur throughout life. Understanding the determinants of infection at different ages is essential to clarify dynamics of $H$. pylori related diseases and to design preventive strategies.

Aim: To estimate the prevalence of $H$. pylori infection at the age of 13 and the incidence after a 3-year follow-up and to identify risk factors for infection.

Subjects and methods: Adolescents born in 1990 were recruited in schools from Porto. Whole-cell antiH. pylori IgG antibodies were quantified by ELISA. Prevalence ratios (PR) and incidence rate ratios (RR) adjusted for parental education were computed at baseline $(n=1312)$ and at follow-up $(n=280)$.

Results: The prevalence was $66.2 \%$, lower in subjects with more educated parents ( $\mathrm{PR}=0.72,95 \% \mathrm{CI}$ : 0.63-0.82), and higher for those having more than one sibling ( $P R=1.10,95 \% \mathrm{CI}: 1.02-1.19)$ and for smokers ( $\mathrm{PR}=1.11,95 \% \mathrm{CI}$ : $1.02-1.20)$. The incidence was $4.1 / 100$ person-years. Smoking $(\mathrm{RR}=2.35$, $95 \% \mathrm{CI}: 1.16-4.75)$ and type of school $(\mathrm{RR}=0.38,95 \% \mathrm{Cl}: 0.16-0.95)$ were associated with the incidence of infection.

Conclusions: Prevalence and incidence of $H$. pylori infection were high, suggesting that gastric cancer will remain an important public health problem in this generation of Portuguese. We identified smoking as a modifiable risk factor for infection.
\end{abstract}

(c) 2012 Editrice Gastroenterologica Italiana S.r.l. Published by Elsevier Ltd. All rights reserved.

\section{Introduction}

Half of the world adult population is infected by Helicobacter pylori [1], a human carcinogen [2] that is acquired mainly in childhood [3]. The prevalence varies appreciably across geographical areas [4,5] and is inversely associated with socioeconomic status or household hygiene and sanitation [6]. Over the last decades, the prevalence of infection in adult populations declined to below $50 \%$ in the more affluent countries of Europe [7-9], and this has contributed to the steep decline in gastric cancer incidence and mortality [10-12]. Despite the steady declines observed in Portugal since the 1970 s $[10,12,13]$, the country presented the highest

\footnotetext{
* Corresponding author at: Departamento de Epidemiologia Clínica, Medicina Preditiva e Saúde Pública, Faculdade de Medicina da Universidade do Porto, Al. Prof. Hernâni Monteiro, 4200-319 Porto, Portugal. Tel.: +351 225513652; fax: +351225513653 .

E-mail address: nlunet@med.up.pt (N. Lunet).
}

gastric cancer incidence (19.2 per 100000 in males and 9.2 per 100000 in females) and mortality rates (15.0 per 100000 men, and 6.8 per 100000 women) in the European Union (27 countries) in 2008 [14].

Age at acquisition of infection is an important determinant of the H.pylori-related gastric outcomes [15]. The birth-cohort pattern observed for gastric and duodenal ulcer could be explained by the decrease in the frequency of $H$. pylori infection accompanied by a simultaneous shift to acquisition at older ages [15]. High prevalence of infection at younger ages is associated with higher gastric cancer mortality than in settings with a similar frequency of infection in older subjects [16] but later acquisition.

Information on the incidence and prevalence of $H$. pylori infection and the understanding of its determinants at different ages may contribute to better understand the relation between this infection and the frequency of gastric cancer, ultimately supporting the definition of a life course framework for gastric pathology research and allowing the estimation of the future burden of gastric disease. Therefore, we aimed to quantify the prevalence of $H$. pylori 
infection at the age of 13 and the incidence after a 3-year follow-up in a cohort of Portuguese adolescents, and to identify risk factors for infection at different ages.

\section{Methods}

A sample of adolescents born in 1990 was recruited in the schools from Porto, Portugal, in 2003/2004 (the EpiTeen cohort). School is compulsory at this age, and virtually all children are registered in a school of their dwelling area. A detailed description of the general selection procedures and participants' characteristics was published before $[17,18]$. In brief, the executive boards of all schools from Porto (27 public and 24 private) allowed the research team to contact the eligible students and their families. In compliant schools [all the public and $19(79 \%)$ of the private], 2787 eligible adolescents were identified (2126 in public and 661 in private schools). We classified as refusals the eligible subjects who did not return the signed informed consent form $(n=583,20.9 \%)$. Those agreeing to participate were contacted at school: 44 students (1.6\%) could not be reached during the evaluation period because were missing classes; the remaining 2160 (1651 public and 509 private school students) provided information at least for part of the planned assessment (Fig. 1). This resulted in a proportion of participants of $77.5 \%$, similar in public and private schools $(77.7 \%$ vs. $76.7 \%, P=0.613$ ) [17].

During the baseline evaluation the participants answered two standardized questionnaires: one was completed by the adolescents at home, with the help of their legal guardians, to obtain data on social, demographic and behavioural characteristics as well as on individual and family history of disease; the other, used to collect information on health behaviours, particularly physical activity, smoking and alcohol consumption, was completed by the adolescents at school, during the visit of the research team. A physical examination was performed at school, between 8 a.m. and 10 a.m., by a team of experienced nurses, nutritionists and physicians, following standardized procedures. A 12-h overnight intravenous blood sample was obtained from 1390 participants. For the present study, we assessed the H. pylori status of 1312 subjects (94.4\%) from which a large enough aliquot was available (Fig. 1).

During a follow-up conducted in 2007/2008, information regarding $H$. pylori infection was available for 280 (63.1\%) participants without evidence of infection at the baseline evaluation (median follow-up: 37 months) (Fig. 1). A random sample, stratified by parental education, of approximately $10 \%$ of the participants with evidence of infection at baseline $(n=76)$ was used to quantify the seroreversion rate (median time of follow-up: 39 months).

Serum samples were kept frozen at $-80^{\circ} \mathrm{C}$ until analysis. Serum anti-H. pylori IgG titres were assessed by ELISA (Anti-H. pylori ELISA, EuroImmun, Lubeck, Germany). The participants' infection status was classified as negative if the antibody concentration was lower than $16 \mathrm{RU} / \mathrm{ml}$, borderline if the antibody concentration was equal or higher than $16 \mathrm{RU} / \mathrm{ml}$ and lower than $22 \mathrm{RU} / \mathrm{ml}$, and positive if the antibody concentration was $22 \mathrm{RU} / \mathrm{ml}$ or higher. For the current analysis, the adolescents with a borderline result (first evaluation: $n=22$; second evaluation: $n=6$ ) were considered infected.

\subsection{Statistical analysis}

For data analysis, parental education was defined as the highest educational level achieved by any one of the parents. The crowding index was calculated as the number of individuals living in the same house over the number of rooms; the cut point used to create a dichotomous variable was 1.3 , which corresponds to the median in this population. The participants were classified as ever or never having tried smoking and alcohol consumption at the age of 13 .
The history of antibiotics use was also assessed in the follow-up evaluation.

Proportions were compared using the $\chi^{2}$ test, or Fisher's exact test, when appropriate. Binomial regression was used to estimate parental education-adjusted prevalence ratios (PR) and the corresponding 95\% confidence intervals $(\mathrm{CI})$. Poisson regression was used to compute parental education-adjusted incidence rate ratios (RR) and the corresponding 95\%CI. The statistical analysis was conducted using STATA ${ }^{\circledR}$, version 9.2.

\subsection{Ethics}

The study was approved by the Ethics Committee of Hospital S. João and written consent was obtained from both legal guardians and adolescents.

\section{Results}

\subsection{Prevalence of $H$. pylori infection at the age of 13}

At baseline, the prevalence of $H$. pylori infection was $66.2 \%$ (95\%CI: 63.6-68.7\%).

As shown in Table 1, there was an inverse association between infection and the mother's and father's education. The adolescents studying in private schools were less likely to be infected (private $v s$. public: $\mathrm{PR}=0.86,95 \% \mathrm{CI}: 0.78-0.96$ ). The prevalence of infection was higher in subjects with more siblings $(>1$ vs. $\leq 1$ : $P R=1.12,95 \% \mathrm{CI}$ : 1.04-1.22), living in houses with a higher crowding index $(>1.3$ vs. $\leq 1.3$ : $\mathrm{PR}=1.09,95 \% \mathrm{CI}: 1.01-1.19$ ) or smokers (ever vs. never: $\mathrm{PR}=1.12$, 95\%CI: 1.03-1.22). No significant associations were found with gender, bathing habits or care in washing hands before handling food (Table 1 ).

After adjustment for parental education, the number of siblings (>1 vs. $\leq 1: \mathrm{PR}=1.10,95 \% \mathrm{CI}: 1.02-1.19$ ) and tobacco consumption (ever vs. never: $\mathrm{PR}=1.11,95 \% \mathrm{CI}: 1.02-1.20$ ) remained statistically significant (Table 1 ).

\subsection{Incidence of $\mathrm{H}$. pylori infection between the ages of 13 and 17}

The incidence rate was 4.1/100 person-years (95\%CI: 3.0-5.8).

A strong positive association was found between smoking at the age of 13 and incidence of $H$. pylori infection (ever $v s$. never: $\mathrm{RR}=2.34,95 \% \mathrm{CI}: 1.16-4.72$ ), even after adjustment for parental education (ever $v s$. never: $\mathrm{RR}=2.35,95 \% \mathrm{CI}$ : 1.16-4.75). Studying in a public school was also a risk factor for the acquisition of $H$. pylori infection, independently from parental education, (private vs. public: $\mathrm{RR}=0.38,95 \% \mathrm{CI}$ : 0.16-0.95) (Table 2).

The seroreversion rate was $1.6 / 100$ person-years $(95 \% \mathrm{CI}$ : $0.6-4.4)$.

\section{Discussion}

The present study allowed us to estimate the point prevalence and the incidence of $H$. pylori infection in a representative sample of urban adolescents. The main findings were that the incidence of $H$. pylori infection was high throughout adolescence, despite the already high prevalence observed at the baseline age of 13 . Social class, represented by parental education, was a relevant determinant of the prevalence at baseline, and smoking was associated with the incidence of infection during adolescence.

The prevalence observed in this study was higher than reported for most European countries, and even many South American, African and Asian settings [19-22], where it ranged from less than $10 \%$ to $64 \%$. The prevalence of infection was $69 \%$ in Vietnam, in adolescents aged between 10 and 14 years evaluated in 2005 [23], 78\% 


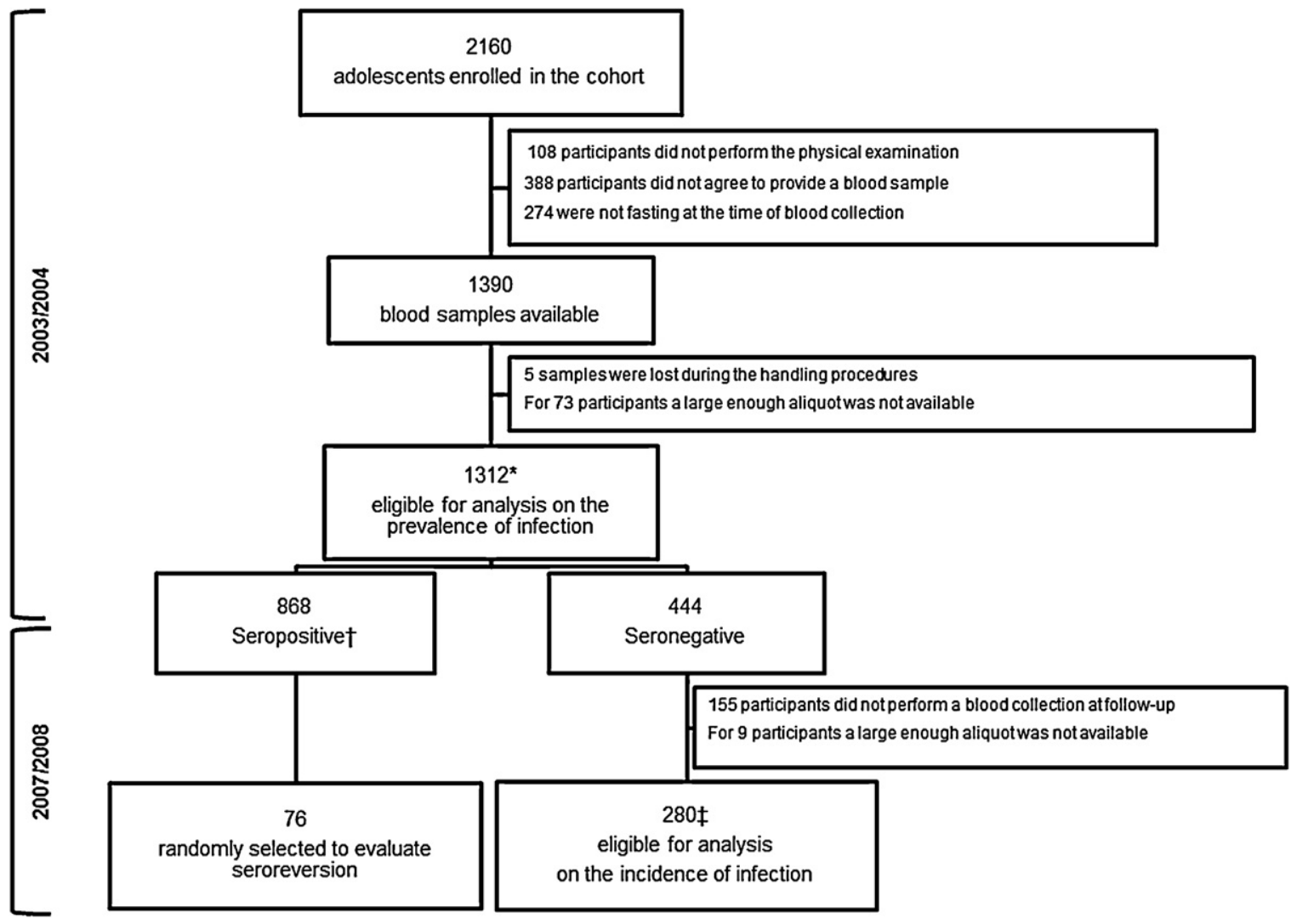

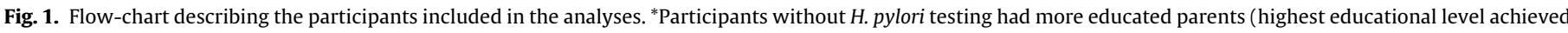

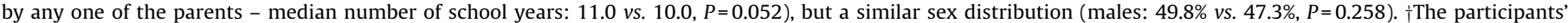

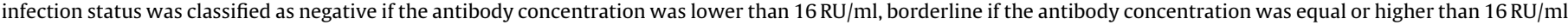

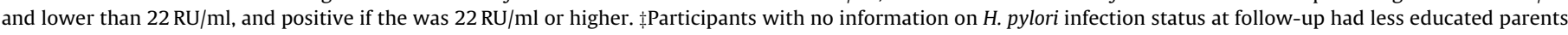
(median number of school years: 11.0 vs. $12.0, P=0.032$ ), but there were no significant differences regarding gender (males: $52.4 \%$ vs. $50.0 \%, P=0.620$ ).

in Rondônia, Brazil, in a sample of participants aged 11-20 years, evaluated in 2010 [24], and $82 \%$ in Iran, in subjects aged below 15 years, evaluated in 2006 [25]. In Portugal, the first national study addressing $H$. pylori prevalence (assessed by serology), published in 1994, showed that the prevalence of infection among children aged between 3 and 14 years was 46.2\% [26]. In a recent study conducted in the south of Portugal, the prevalence of $H$. pylori infection (assessed by stool antigen test) in children aged between 3 and 14 years of age was $39.3 \%$, and $51.5 \%$ in children aged between 11 and 15 years [27]. The prevalence found in our study is higher, which explains the higher gastric cancer incidence found in the North of Portugal [13,28].

Direct comparisons between studies assessing the frequency of $H$. pylori infection in adolescents is hampered by the diversity of age ranges, duration of follow-up, types of populations and characteristics of the diagnostic tools. The annual rates of seroconversion ranged from $0.1 \%$ to $1.9 \%$ in adolescents from high income countries, as assessed in the late 1990s [19]. In more recent studies, the annual rates were $1.5 \%$ in Japan [29], $1.4 \%$ in the USA [30], $2.5 \%$ in Turkey [31] and 7.0\% in Turkish children living in Germany $[31,32]$. In a study from the South of Portugal, conducted between 2003 and 2006 it was 10.5/100 child-years in the age group 11-15 years [27], though only $52 \%$ participated in the follow-up study and from these $60 \%$ were lost during the 3 -year follow-up.

A poor socio-economic condition favours infection, likely through poor sanitation, deficient hygiene and overcrowding [33-35]. We used education of the parents and type of school attended (private or public) as a surrogate measure of socio-economic status, and confirmed its importance as a determinant of infection. When including other potential markers of socioeconomic status in the model, such as smoking and alcohol consumption, the results remained essentially unchanged (data not shown). The number of siblings and household overcrowding during childhood reflect the probability of close contacts with infected individuals and has also been associated with $H$. pylori infection [30,36-38]. Our results confirm the role of the number of siblings for the occurrence of infection in the childhood but not in adolescence. However, the interpretation of this result is limited by the fact that we were not able to measure $H$. pylori infection in the household members. The crowding index was based on the information collected at 13 years and it may not totally reflect the crowding conditions during early childhood, which may have contributed to the lack of association between this exposure and infection at the baseline; on the other hand, it is a measure of the crowding conditions in adolescence, and the lack of its association with the acquisition of infection is likely to reflect the more important effect of other factors than family close contacts for the acquisition of the infection at these ages.

We also evaluated bathing and hand-washing habits and hygiene in handling foods, but we found no associations with infection in these adolescents. A previous analysis of this dataset showed that the lowest hand washing frequency was associated with higher probability of diarrhoea occurrence [39], and therefore it is unlikely that the lack of association observed in the present investigation reflects underestimation due to social desirability bias [40].

Although controversial, there is a body of evidence regarding the relation between smoking and $H$. pylori infection [6]. The fact that tobacco smoking is associated with other lifestyles and with nutritional status [41-44] may contribute to the conflicting 
Table 1

Factors associated with the prevalence of $H$. pylori infection at the age of 13 .

\begin{tabular}{|c|c|c|c|c|}
\hline & $N$ & H. pylori-infected, $n$ (\%) & Crude PR (95\%CI) & Adjusted $^{\mathrm{a}} \mathrm{PR}(95 \% \mathrm{CI})$ \\
\hline \multicolumn{5}{|l|}{ Mother's education ${ }^{\mathrm{b}}$} \\
\hline$\leq 4$ years & 311 & $227(72.3)$ & 1.00 & - \\
\hline $5-9$ years & 406 & $286(70.4)$ & $0.96(0.88-1.06)$ & - \\
\hline $10-12$ years & 282 & $164(58.2)$ & $0.80(0.71-0.90)$ & - \\
\hline$>12$ years & 254 & $141(55.5)$ & $0.76(0.67-0.87)$ & - \\
\hline \multicolumn{5}{|l|}{ Father's education ${ }^{\mathrm{b}}$} \\
\hline$\leq 4$ years & 289 & $210(72.7)$ & 1.00 & - \\
\hline $5-9$ years & 408 & $273(66.9)$ & $0.92(0.83-1.02)$ & - \\
\hline 10-12 years & 291 & $181(62.2)$ & $0.86(0.76-0.96)$ & - \\
\hline$>12$ years & 215 & $112(52.1)$ & $0.72(0.62-0.83)$ & - \\
\hline \multicolumn{5}{|l|}{ Parental education ${ }^{\mathrm{b}}$} \\
\hline$\leq 4$ years & 189 & $144(76.2)$ & 1.00 & \\
\hline $5-9$ years & 438 & $311(71.0)$ & $0.93(0.84-1.03)$ & \\
\hline 10-12 years & 326 & $200(61.4)$ & $0.80(0.72-0.90)$ & - \\
\hline$>12$ years & 310 & $170(54.8)$ & $0.72(0.63-0.82)$ & - \\
\hline \multicolumn{5}{|l|}{ Type of school } \\
\hline Public & 996 & $681(68.4)$ & 1.00 & 1.00 \\
\hline Private & 316 & $187(59.2)$ & $0.86(0.78-0.96)$ & $0.93(0.83-1.03)$ \\
\hline \multicolumn{5}{|l|}{ Gender } \\
\hline Females & 691 & $473(68.4)$ & 1.00 & 1.00 \\
\hline Males & 621 & $395(63.6)$ & $0.93(0.86-1.00)$ & $0.92(0.85-1.00)$ \\
\hline \multicolumn{5}{|l|}{ Number of siblings ${ }^{b}$} \\
\hline$\leq 1$ & 892 & $564(63.2)$ & 1.00 & 1.00 \\
\hline$>1$ & 401 & $285(71.1)$ & $1.12(1.04-1.22)$ & $1.10(1.02-1.19)$ \\
\hline \multicolumn{5}{|l|}{ Crowding index ${ }^{\mathrm{b}}$} \\
\hline$\leq 1.3$ & 392 & $242(61.7)$ & 1.00 & 1.00 \\
\hline$>1.3$ & 872 & $587(67.3)$ & $1.09(1.01-1.19)$ & $1.05(0.96-1.15)$ \\
\hline \multicolumn{5}{|l|}{ Smoking ${ }^{\mathrm{b}}$} \\
\hline Never tried & 958 & $612(63.9)$ & 1.00 & 1.00 \\
\hline Ever tried & 308 & $220(71.4)$ & $1.12(1.03-1.22)$ & $1.11(1.02-1.20)$ \\
\hline \multicolumn{5}{|l|}{ Alcohol drinking ${ }^{\mathrm{b}}$} \\
\hline Never tried & 575 & $390(67.8)$ & 1.00 & 1.00 \\
\hline Ever tried & 688 & $438(63.7)$ & $0.94(0.87-1.02)$ & $0.96(0.89-1.04)$ \\
\hline \multicolumn{5}{|l|}{ Bath habits ${ }^{\mathrm{b}}$} \\
\hline Bath $\geq 4$ times/week & 1158 & $755(65.2)$ & 1.00 & 1.00 \\
\hline Bath $<4$ times/week & 132 & $92(69.7)$ & $1.07(0.95-1.21)$ & $1.06(0.94-1.19)$ \\
\hline \multicolumn{5}{|c|}{ Washing hands before handling food ${ }^{\mathrm{b}}$} \\
\hline Always & 913 & $604(66.2)$ & 1.00 & 1.00 \\
\hline Not always & 379 & $244(64.4)$ & $0.97(0.89-1.06)$ & $1.02(0.93-1.11)$ \\
\hline
\end{tabular}

PR, prevalence ratio; 95\%CI, 95\% confidence interval.

a Adjusted for parental education (highest educational level achieved by any one of the parents).

b The sum of participants in each class is lower than the total $(n=1312)$ due to missing information.

findings on this topic. In our study, we opted for providing the PR and RR estimates adjusted only for parental education, because the point estimates did not vary meaningfully when BMI (above the 95th percentile, between the 85th and the 95th percentile and below the 85th percentile, as recommended for children and adolescents according to the age- and sex-specific BMI reference percentiles developed by the United States Centers for Disease Control and Prevention $[45,46]$ ) or dietary patterns were included in the model. This may reflect the fact that parental education is a surrogate for socioeconomic status and lifestyle exposures, but also the lack of association between each of the latter and $H$. pylori infection. In our study, after adjustment for parental education we did not find significant associations between BMI and $H$. pylori infection, (above the 95 th percentile $v s$. below the 85 th percentile: $\mathrm{PR}=0.92,95 \% \mathrm{CI}: 0.80-1.06$; between the 85th and the 95th percentile $v$ s. below the 85 th percentile: $\mathrm{PR}=0.92,95 \% \mathrm{CI}$ : $0.75-1.12$ ) or between dietary patterns (unpublished results) and infection ("High calorie" vs. "Healthy": PR=1.01, 95\%CI: 0.84-1.22; "Low calorie" vs. "Healthy"; PR =1.08, 95\%CI: 0.93-1.25; "Undifferentiated" vs. "Healthy": $\mathrm{PR}=0.96,95 \% \mathrm{CI}$ : 0.81-1.13). When including smoking habits in these models, the point estimates remained essentially unchanged. Although the association observed in our study between tobacco use and infection is relatively weak, it is biologically plausible and smoking was also shown to contribute for the failure of $H$. pylori eradication [47]. Our results show that there is potential for intervention in the reduction of $H$. pylori infection during adolescence and this should be taken into account when estimating the potential benefits of tobacco control measures at early ages. A greater frequency of $H$. pylori infection in smokers may also at least in part contribute to explain the relation between tobacco and gastric cancer $[12,48]$. On the other hand, the lack of association between alcohol consumption and infection is in accordance with previous reports [6].

Our results show that nearly 16 in each $1000 \mathrm{H}$. pylori infected adolescents undergo seroreversion each year. In one of these adolescents a short course of antibiotics for respiratory disease had been prescribed a few months before the follow-up assessment, but no history of use of antibiotics was reported in the same period for the remaining. Serologic tests in children are not as accurate as in adults [49]; although using the cut-off values defined for adults may yield a lower sensitivity in infants, after the age of 12 years sensitivity and specificity become as high as in adults [49]. According to the manufacturer's description of the product, the test used to assess infection status in the present investigation has a sensitivity of $100 \%$ and a specificity of $94 \%$, in adults. We classified the participants with borderline serum IgG titres as infected, but the results were not meaningfully different when participants with borderline results were considered not infected (data not shown). Furthermore, the declines in the antibody concentration of the participants in whom seroreversion was observed ranged between $72 \%$ 
Table 2

Factors associated with the incidence of $H$. pylori infection after the age of 13 .

\begin{tabular}{|c|c|c|c|c|c|}
\hline & $N$ & Incident cases of infection & Person-years at risk & Crude RR (95\%CI) & Adjusted $^{\mathrm{a}} \mathrm{RR}(95 \% \mathrm{CI})$ \\
\hline \multicolumn{6}{|l|}{ Mother's education } \\
\hline$\leq 4$ years & 48 & 7 & 144 & 1.00 & - \\
\hline $5-9$ years & 75 & 9 & 233 & $0.79(0.30-2.13)$ & - \\
\hline $10-12$ years & 71 & 10 & 213 & $0.96(0.37-2.54)$ & - \\
\hline$>12$ years & 86 & 9 & 256 & $0.72(0.27-1.94)$ & - \\
\hline \multicolumn{6}{|l|}{ Father's education ${ }^{b}$} \\
\hline$\leq 4$ years & 52 & 8 & 158 & 1.00 & - \\
\hline $5-9$ years & 81 & 11 & 246 & $0.88(0.35-2.20)$ & - \\
\hline $10-12$ years & 66 & 6 & 202 & $0.59(0.20-1.69)$ & - \\
\hline$>12$ years & 77 & 10 & 226 & $0.87(0.34-2.21)$ & - \\
\hline \multicolumn{6}{|l|}{ Parental education } \\
\hline$\leq 4$ years & 31 & 5 & 92 & 1.00 & - \\
\hline $5-9$ years & 74 & 8 & 232 & $0.63(0.21-1.94)$ & \\
\hline $10-12$ years & 70 & 9 & 213 & $0.78(0.26-2.32)$ & \\
\hline$>12$ years & 105 & 13 & 309 & $0.77(0.28-2.17)$ & - \\
\hline \multicolumn{6}{|l|}{ Type of school } \\
\hline Public & 190 & 29 & 570 & 1.00 & 1.00 \\
\hline Private & 90 & 6 & 276 & $0.43(0.18-1.03)$ & $0.38(0.16-0.95)$ \\
\hline \multicolumn{6}{|l|}{ Gender } \\
\hline Females & 140 & 15 & 431 & 1.00 & 1.00 \\
\hline Males & 140 & 20 & 415 & $1.38(0.71-2.70)$ & $1.39(0.71-2.71)$ \\
\hline \multicolumn{6}{|l|}{ Number of siblings } \\
\hline$\leq 1$ & 210 & 23 & 635 & 1.00 & 1.00 \\
\hline$>1$ & 70 & 12 & 211 & $1.57(0.78-3.16)$ & $1.58(0.78-3.17)$ \\
\hline \multicolumn{6}{|l|}{ Crowding index $\mathrm{b}$} \\
\hline$\leq 1.3$ & 98 & 13 & 292 & 1.00 & 1.00 \\
\hline$>1.3$ & 178 & 21 & 542 & $0.87(0.44-1.74)$ & $0.88(0.44-1.75)$ \\
\hline \multicolumn{6}{|l|}{ Smoking ${ }^{\mathrm{b}}$} \\
\hline Never tried & 218 & 22 & 664 & 1.00 & 1.00 \\
\hline Ever tried & 53 & 12 & 155 & $2.34(1.16-4.72)$ & $2.35(1.16-4.75)$ \\
\hline \multicolumn{6}{|l|}{ Alcohol drinking ${ }^{\mathrm{b}}$} \\
\hline Never tried & 112 & 16 & 341 & 1.00 & 1.00 \\
\hline Ever tried & 164 & 19 & 492 & $0.82(0.42-1.60)$ & $0.82(0.42-1.60)$ \\
\hline \multicolumn{6}{|l|}{ Bath habits ${ }^{\mathrm{b}}$} \\
\hline Bath $\geq 4$ times/week & 250 & 30 & 757 & 1.00 & 1.00 \\
\hline Bath $<4$ times/week & 29 & 5 & 86 & $1.47(0.57-3.78)$ & $1.47(0.57-3.78)$ \\
\hline \multicolumn{6}{|c|}{ Washing hands before handling food } \\
\hline Always & 186 & 24 & 569 & 1.00 & 1.00 \\
\hline Not always & 94 & 11 & 277 & $0.94(0.46-1.92)$ & $0.94(0.46-1.92)$ \\
\hline
\end{tabular}

$\mathrm{RR}$, incidence rate ratio; $95 \% \mathrm{CI}, 95 \%$ confidence interval.

a Adjusted for parental education (highest educational level achieved by any one of the parents).

b The sum of participants in each class is lower than the total $(n=280)$ due to missing information.

and $99 \%$, supporting the hypothesis of a previous infection that was resolved.

Two patterns of $H$. pylori prevalence in respect to age have been described. In middle and low income countries infection is acquired mainly in childhood and may reach nearly $100 \%$ during adulthood. In high income countries, the infection is less common in young children and gradually increases with age [5]. Portugal presents a very high prevalence of infection in adolescence, similarly to what is observed in middle and low income settings, but also a high incidence between the ages of 13 and 17, showing that the acquisition in this period is not negligible and contributes for the high prevalence later in life.

In conclusion, approximately two-thirds of these Portuguese 13 year-old were infected with $H$. pylori, and the incidence of infection remained high during the adolescence. Our results suggest that stomach cancer incidence and mortality in Portugal are likely to remain among the highest in Europe.

\section{Conflict of interest statement}

The authors declare that there are no conflicts of interest to disclose.

\section{Sources of support}

Grants from 'Fundação para a Ciência e a Tecnologia' (PTDC/SAUESA/103958/2008, PTDC/SAU-EPI/115254/2009, POCTI/SAU$\mathrm{ESP} / 62399 / 2004$ and $\mathrm{SFRH} / \mathrm{BD} / 41504 / 2007)$ are gratefully acknowledged. The work of CLV was supported by the 'Associazione Italiana per la Ricerca sul Cancro' (AIRC, Grant No. 10068). The authors report no other sources of founding.

\section{References}

[1] Parkin DM. The global health burden of infection-associated cancers in the year 2002. International Journal of Cancer 2006;118:3030-44.

[2] International Agency for Research on Cancer Working Group on the Evaluation of Carcinogenic Risks to Humans. Schistosomes, liver flukes and Helicobacter pylori. In: IARC., editor. IARC monographs on the evaluation of carcinogenic risks to humans. Lyon: IARC; 1994.

[3] Cullen DJ, Collins BJ, Christiansen KJ, et al. When is Helicobacter pylori infection acquired. Gut 1993;34:1681-2.

[4] Lunet N, Barros H. Helicobacter pylori infection and gastric cancer: facing the enigmas. International Journal of Cancer 2003;106:953-60.

[5] Lunet N, Barros H. Helicobacter pylori infection and gastric cancer in developing countries: revisiting the enigmas. In: Ly A, Khayat D, editors. About cancer in Africa: from epidemiology to biomedical applications and perspectives. Paris: INCA; 2006.

[6] Brown LM. Helicobacter pylori: epidemiology and routes of transmission. Epidemiologic Reviews 2000;22:283-97.

[7] Asfeldt AM, Straume B, Steigen SE, et al. Changes in the prevalence of dyspepsia and Helicobacter pylori infection after 17 years: the Sorreisa gastrointestinal disorder study. European Journal of Epidemiology 2008;23:625-33.

[8] Harvey RF, Spence RW, Lane JA, et al. Relationship between the birth cohort pattern of Helicobacter pylori infection and the epidemiology of duodenal ulcer. QJM: Monthly Journal of the Association of Physicians 2002;95 519-25.

[9] Gause-Nilsson I, Gnarpe H, Gnarpe J, et al. Helicobacter pylori serology in elderly people: a 21-year cohort comparison in 70-year-olds and a 20 -year longitudinal population study in 70-90-year-olds. Age and Ageing 1998;27:433-6. 
[10] Levi F, Lucchini F, Gonzalez JR, et al. Monitoring falls in gastric cancer mortality in Europe. Annals of Oncology 2004;15:338-45.

[11] Kamangar F, Dores GM, Anderson WF. Patterns of cancer incidence, mortality, and prevalence across five continents: defining priorities to reduce cancer disparities in different geographic regions of the world. Journal of Clinical Oncology 2006;24:2137-50.

[12] Bertuccio P, Chatenoud L, Levi F, et al. Recent patterns in gastric cancer: a global overview. International Journal of Cancer 2009;125:666-73.

[13] Lunet N, Pina F, Barros H. Regional trends in Portuguese gastric cancer mortality (1984-1999). European Journal of Cancer Prevention 2004;13:271-5.

[14] Ferlay J, Shin HR, Bray F, et al. GLOBOCAN 2008: cancer incidence and mortality worldwide: IARC CancerBase No. 10 [Internet]. Lyon, France: International Agency for Research on Cancer; 2010. Available from: http://globocan.iarc.fr

[15] Sonnenberg A. Causes underlying the birth-cohort phenomenon of peptic ulcer: analysis of mortality data 1911-2000, England and Wales. International Journal of Epidemiology 2006;35:1090-7.

[16] Ferreccio C, Rollan A, Harris PR, et al. Gastric cancer is related to early Helicobacter pylori infection in a high-prevalence country. Cancer Epidemiology, Biomarkers and Prevention 2007; 16:662-7.

[17] Ramos E, Barros H. Family and school determinants of overweight in 13-yearold Portuguese adolescents. Acta Paediatrica 2007;96:281-6.

[18] Ramos E, Barros H. Prevalence of hypertension in 13-year-old adolescents in Porto, Portugal. Revista Portuguesa de Cardiologia 2005;24: 1075-87.

[19] Torres J, Perez-Perez G, Goodman KJ, et al. A comprehensive review of the natural history of Helicobacter pylori infection in children. Archives of Medical Research 2000;31:431-69.

[20] Sykora J, Siala K, Varvarovska J, et al. Epidemiology of Helicobacter pylori infection in asymptomatic children: a prospective population-based study from the Czech Republic. Application of a monoclonal-based antigen-in-stool enzyme immunoassay. Helicobacter 2009;14:286-97.

[21] Kori M, Goldstein E, Granot E. Helicobacter pylori infection in young children detected by a monoclonal stool antigen immunoassay. Pediatric Infectious Disease Journal 2009;28:157-9.

[22] Yucel O, Sayan A, Yildiz M. The factors associated with asymptomatic carriage of Helicobacter pylori in children and their mothers living in three socio-economic settings. Japanese Journal of Infectious Diseases 2009;62:120-4.

[23] Hoang TT, Bengtsson C, Phung DC, et al. Seroprevalence of Helicobacter pylori infection in urban and rural Vietnam. Clinical and Diagnostic Laboratory Immunology 2005;12:81-5.

[24] Ribeiro RB, Martins HS, Dos Santos VA, et al. Evaluation of Helicobacter pylory colonization by serologic test (IgG) and dyspepsia in volunteers from the countryside of Monte Negro, in the Brazilian western Amazon region. Revista do Instituto de Medicina Tropical de Sao Paulo 2010;52:203-6.

[25] Alborzi A, Soltani J, Pourabbas B, et al. Prevalence of Helicobacter pylori infection in children (south of Iran). Diagnostic Microbiology and Infectious Disease 2006;54:259-61.

[26] Quina MG. Helicobacter pylori: the Portuguese scene. Grupo de Estudo Portugues do Helicobacter pylori (GEPHP). European Journal of Cancer Prevention 1994;3(Suppl. 2):65-7.

[27] Oleastro M, Pelerito A, Nogueira P, et al. Prevalence and incidence of Helicobacter pylori infection in a healthy pediatric population in the Lisbon area. Helicobacter 2011;16:363-72.

[28] Lunet N. Helicobacter pylori infection in a region with high risk of gastric cancer. Arquivos de Medicina 2011;25:213-7 [in Portuguese].

[29] Naito Y, Shimizu T, Haruna H, et al. Changes in the presence of urine Helicobacter pylori antibody in Japanese children in three different age groups. Pediatrics International 2008;50:291-4.
[30] Dore MP, Malaty HM, Graham DY, et al. Risk factors associated with Helicobacter pylori infection among children in a defined geographic area. Clinical Infectious Diseases 2002;35:240-5.

[31] Ozen A, Ertem D, Pehlivanoglu E. Natural history and symptomatology of Helicobacter pylori in childhood and factors determining the epidemiology of infection. Journal of Pediatric Gastroenterology and Nutrition 2006;42:398-404.

[32] Rothenbacher D, Bode G, Brenner H. Dynamics of Helicobacter pylori infection in early childhood in a high-risk group living in Germany: loss of infection higher than acquisition. Alimentary Pharmacology and Therapeutics 2002;16:1663-8.

[33] Goodman KJ, Correa P, Tengana Aux HJ, et al. Helicobacter pylori infection in the Colombian Andes: a population-based study of transmission pathways. American Journal of Epidemiology 1996;144:290-9.

[34] Fallone CA. Determinants of ethnic or geographical differences in infectivity and transmissibility of Helicobacter pylori. Canadian Journal of Gastroenterology 1999;13:251-5.

[35] Kivi M, Tindberg Y. Helicobacter pylori occurrence and transmission: a family affair. Scandinavian Journal of Infectious Diseases 2006;38:407-17.

[36] Ford AC, Forman D, Bailey AG, et al. Effect of sibling number in the household and birth order on prevalence of Helicobacter pylori: a cross-sectional study. International Journal of Epidemiology 2007;36:1327-33.

[37] Goodman KJ, Correa P. Transmission of Helicobacter pylori among siblings. Lancet 2000;355:358-62.

[38] Gao L, Weck MN, Raum E, et al. Sibship size, Helicobacter pylori infection and chronic atrophic gastritis: a population-based study among 9444 older adults from Germany. International Journal of Epidemiology 2009;39:129-34.

[39] Gomes A, Fraga S, Ramos E. Hand washing and diarrhoea in adolescents. Journal of Public Health 2011;19:401-7.

[40] McDowell I, Newell C. Measuring health: a guide to rating scales and questionnaires. 2nd ed. Oxford: Oxford University Press; 1996.

[41] Dallongeville J, Marecaux N, Fruchart JC, et al. Cigarette smoking is associated with unhealthy patterns of nutrient intake: a meta-analysis. Journal of Nutrition 1998;128:1450-7.

[42] Padrao P, Lunet N, Santos AC, et al. Smoking, alcohol, and dietary choices: evidence from the Portuguese National Health Survey. BMC Public Health 2007;7:138.

[43] Padrao P, Silva-Matos C, Damasceno A, et al. Association between tobacco consumption and alcohol, vegetable and fruit intake across urban and rural areas in Mozambique. Journal of Epidemiology and Community Health 2011;65:445-53.

[44] Sneve M, Jorde R. Cross-sectional study on the relationship between body mass index and smoking, and longitudinal changes in body mass index in relation to change in smoking status: the Tromso Study. Scandinavian Journal of Public Health 2008;36:397-407.

[45] Kuczmarski RJ, Ogden CL, Guo SS, et al. 2000 CDC Growth Charts for the United States: methods and development. Vital and Health Statistics 2002;11:1-190.

[46] Daniels SR, Arnett DK, Eckel RH, et al. Overweight in children and adolescents: pathophysiology, consequences, prevention, and treatment. Circulation 2005;111:1999-2012.

[47] Suzuki T, Matsuo K, Ito H, et al. Smoking increases the treatment failure for Helicobacter pylori eradication. American Journal of Medicine 2006;119:217-24.

[48] Sasco AJ, Secretan MB, Straif K. Tobacco smoking and cancer: a brief review of recent epidemiological evidence. Lung Cancer 2004;45(Suppl. 2):S3-9.

[49] de Oliveira AM, Rocha GA, Queiroz DM, et al. Evaluation of enzyme-linked immunosorbent assay for the diagnosis of Helicobacter pylori infection in children from different age groups with and without duodenal ulcer. Journal of Pediatric Gastroenterology and Nutrition 1999;28:157-61. 